\title{
Religiosamente irreligiosos. Ateos, agnósticos y nones en Roma*
}

\author{
Verónica Roldán** \\ Simona Scotti**
}

\section{Resumen}

El estudio aquí presentado se propone indagar sobre las principales características de la "no-religiosidad" de un grupo de personas autodefinidas "ateas", "agnósticas" y "nones" (es decir, creyentes en una entidad superior pero que no se identifican con ninguna institución religiosa) residentes en la ciudad de Roma, Italia. Se ha indagado, en particular, sobre su socialización religiosa, su visión respecto la religión, la trascendencia y la espiritualidad y su relación con la tradición cultural y religiosa nacional al fin de relevar las nuevas definiciones y sensibilidades de los « sin religión » en la Ciudad Eterna.

Palabras claves: ateos, agnósticos, nones, socialización religiosa, Roma.

\section{Religiously irreligious. Atheists, agnostics and nones in Rome}

\section{Abstract}

The study presented here aims to investigate the main characteristics of the "non-religiosity" of a group of atheists, agnostics and nones, residents in Rome, Italy. In particular, the analysis focuses on the religious socialization, the vision of religion, transcendence and spirituality and their relationship with the cultural and religious tradition of the nation.

Keywords: atheists, agnostics, nones, religious socialization, Rome.

* Los parágrafos: Introducción. I. El pluralismo en el contexto religioso italiano. IV. La búsqueda del sentido. La dimensión de la experiencia y los valores, son de Simona Scotti. Los parágrafos: II. La metodología de la investigación. III. La vivencia de la no-religiosidad en Roma. Socialización religiosa, creencias y prácticas, son de Verónica Roldán.

Las Conclusiones fueron escritas por las dos autoras.

** PhD en Sociología y Metodología de la Investigación Social; docente en la Universidad Roma Tre, Italia. veronica.roldan@uniroma3.it

*** $\mathrm{PhD}$ en Calidad de la Formación; docente de Metodología de la Formación activa- training for change en la Universidad de Florencia, Italia.simonascotti@inwind.it 


\section{Introducción}

La subjetivación y la desinstitucionalización son los aspectos de la modernidad que contribuyen a hacer « líquida » la experiencia de los individuos (BAUMAN, 1999) y lo que sucede en el contexto religioso es particularmente significativo. Con la globalización, los mundos simbólicos se hacen más complejos. El encuentro o enfrentamiento de las culturas, la diversidad de hábitos y actitudes hacen que la experiencia de los individuos adquiera una forma cada vez más plural.

El pluralismo, por rende, se presenta como uno de los principales paradigmas de la modernidad, además de la teoría de la secularización que durante mucho tiempo ha sido la clave interpretativa de los fenómenos religiosos contemporáneos. Peter Berger convencido de que las evidencias sociales implican una necesidad de «reubicación» de la teoría de la secularización, en su libro The Many Altars of Modernity: Toward a Paradigm for Religion in a Pluralist Age (2014), propone el paradigma del pluralismo para explicar las características socioculturales de nuestras sociedades, no sólo en el ámbito de la religión. Los individuos de hoy en día experimentan la diversidad, la interiorizan, hacen uso personal de los aspectos que consideran más significativos y más convincentes. La teoría del « bricolage religioso » (BASTIAN 2001, Lucà TrombetTA, 2004) y aquella del « mercado religioso ${ }^{1}{ }^{2}$ entre otras, se convierten en aspectos de esta actitud renovada que crea órdenes simbólicos personalizados más allá de las instituciones clásicas de referencia.

En una publicación reciente, Luca Diotallevi (2017) aborda la cuestión del fin del cristianismo confesional en Europa, es decir de esa forma de religión que durante mucho tiempo ha contribuido a la definición de la identidad pública y la legitimidad del poder político, desempeñando una función de 'infraestructura estatal'. En un momento de desinstitucionalización ${ }^{2}$ como el que estamos viviendo, lo que ha sido el marco de la identidad europea desde el siglo XVI hasta hoy, ya no desempeña la misma función.

\footnotetext{
El «paradigma de la economía religiosa» fue propuesto a mediados de la década de 1980 en América del Norte por Rodney Stark, William S. Bainbridge, Roger Finke y Laurence R. Iannaccone (cfr. Stark, Introvigne 2003) ; para la situación italiana cfr. Pisati, MarCHisio, 1998; Magister, 1998.

2 La modernidad pluralista nos obliga a reexaminar los nomos, es decir, lo que consideramos objetivamente válido porque está institucionalizado. La religión también se somete a este pasaje porque ya no es, naturalmente, el lugar y la familia donde el individuo nace, sino el resultado de una elección entre las muchas posibles, incluida la de no tener fe y considerarse agnóstico, ateo o nones. De este proceso de desinstitucionalización, habla Peter Berger (2014), entre otros, también Zigmunt Bauman (2006) en relación con los procesos de producción, en el sentido de que el Estado ya no brinda servicios para para superar la incertidumbre del hombre.
} 
Según Berger y Luckmann (1966), la institución es una "estructura de verosimilitud" que sostiene en modo casi obvio algunas actitudes y comportamientos compartidos y, en el caso de algunas tradiciones religiosas, contribuye a la gestión de la duda. En consecuencia, en la modernidad, las estructuras de verosimilitud se multiplican; hay nuevas modalidades, a veces muy complejas, de gestión de la experiencia religiosa, de subjetivización que sustituye cada vez más a los mecanismos objetivos de las trayectorias definidas institucionalmente.

¿Cómo definir la figura de ateos y agnósticos en este panorama complejo? Así como es difícil definir la pertenencia a un universo caracterizado por la fluidez, es igualmente difícil concebir su distancia: ¿lejos de quién? ¿Lejos de qué?

El estudio aquí presentado tiene como objetivo analizar las principales características de la "no-religiosidad" de un grupo de personas autodefinidas "ateas", "agnósticas" y "nones" (es decir, creyentes en una entidad superior pero no identificadas con ninguna institución religiosa) y que interpretan la « no-creencia » a partir de motivaciones personales y culturales múltiples. Se ha indagado, en particular, sobre su socialización religiosa, su visión respecto la religión, la trascendencia y la espiritualidad y su relación con la tradición cultural y religiosa nacional al fin de relevar las nuevas definiciones y sensibilidades de los «sin religión » en la Ciudad Eterna.

\section{El pluralismo en el contexto religioso italiano}

El caso italiano ciertamente representa un ejemplo particular de este pluralismo (Garelli, Guizzardi, Pace, 2003; Garelli, 2006, Diotallevi, 2001). La cultura básica está inundada de catolicismo, un elemento religioso y cultural tan penetrante que debe considerarse, directa o indirectamente, como parte de la experiencia de socialización primaria de la totalidad de los italianos (Cipriani, 2017). Con la cultura católica, los italianos seguramente tienen contacto aunque sea solo por contraste (BERZANo, 2017a).

Se considere, por ejemplo la enseñanza de la religión católica en las escuelas públicas donde, para no asistir a esa materia, es necesario hacer una declaración de renuncia ${ }^{3}$. La cultura católica, en Italia, es casi un "dato

\footnotetext{
Personas que renuncian a la hora de religión en la escuela pública IRC (datos nacionales) Año lectivo 2014/2015, Total 87,9 \%; Jardín de infantes 91,3\%; escuela primaria 92,3\%; Secundario de I grado 89,9\%; Secundaria d5 II grado 80,7\% . Fuente:

http://www.chiesacattolica.it/cci new v3/s2magazine/vedidocAreaRiservata.jsp?id allegato $=74312$
} 
obvio", y quienes deciden no compartirla, aunque sea solo para distanciarse, deben constatar su existencia y significatividad también en el ámbito público, como es por ejemplo, la escuela.

Si se hace referencia a las cinco dimensiones clásicas de religiosidad (GLOCK, 1969), creencia, experiencia, practica, pertenencia y conocimiento religioso, nos encontramos en un primer momento dentro de la dimensión del "conocimiento": en Italia las personas, aunque de una manera cualitativamente muy diferenciada, son conscientes de la existencia de un cosmos simbólico que se refiere al contexto socio-geográfico nacional. Lo que cambia, sin duda, es la dimensión de la "creencia religiosa", a menudo asociada a la anterior, ya que se la considera casi conseguente: (¿Cómo puedo creer si no conozco?).

En Italia, quienes deciden no creer deben, de todos modos, lidiar con la presencia de una dimensión cultural influente, de la cual tienen que declarar que toman distancia.

En Italia, en las últimas décadas, se puede observar un crecimiento del porcentaje de personas que se definen «sin religión»: los datos de una investigación nacional llevada a cabo en 1994-1995 sobre la religiosidad de los italianos relevaron la cifra del 8.8\% (CESAREO ET AL. 1995, p. 113). ${ }^{4}$ En una indagación posterior, diseñada según el modelo de esta precedente, pero realizada a nivel local en algunas zonas de la Toscana, emerge una tendencia al aumento del porcentaje de los "sin religión" que alcanza el 12\% de los entrevistados (SсотTI , 2002). Y según una investigación más reciente, dirijida por el sociólogo Franco Garelli, cuyos resultados fueron publicados en la obra intitulada Religione all'italiana. L'anima del paese messa a nudo (GARELLI, 2011), la cifra de los ateos es del $6.6 \%$ y de los agnósticos del $6.2 \%{ }^{5}$, por un total de los "sin religión" que alcanza el 12,8 \%. Sin embargo, en este estudio se ha relevado un gran número de respuestas abiertas a la trascendencia, por lo que se puede afirmar que existe un singular modo italiano de ateísmo, representado por una minoría de no creyentes que están abiertos al discurso religioso.

La "no creencia" es una categoría bajo la cual se encuentran definiciones y sensibilidad particulares. Nos encontramos en el tiempo de las « religiones

4 Para otros datos sobre la no creencia en Italia, del 2014, cfr. http://www.doxa.it/religiosita-e-ateismo-in-italia-nel-2014/

5 Esto es lo que surge de la investigación Una investigación encargada a la agencia de sondajes Eurisko, con entrevistas a 3.160 italianos de entre 16 y 74 años de edad. Los datos fueron luego elaborados por un grupo de trabajo del Departamento de Ciencias Sociales de la Universidad de Turín. 
inestables », afirma Garelli en otra investigación nacional cualitativa-cuantitativa más reciente que se centra en el ateismo de los jóvenes de entre 18 y 29 años que viven en los más diversas áreas italianas (GARELLI, 2016).

Desde un punto de vista cultural, deben tenerse en cuenta también los efectos de la globalización y el fenómeno de las «identidades reactivas» resaltado por Stefano Allievi (2005, 2006), que se definen por contraste a la diversidad actual. De aquí provienen aquellos que, en lenguaje periodístico, son definidos «ateos devotos » (SorBI, 2007).

Es interesante observar que en el actual escenario social italiano, caracterizado por una creciente - no siempre serena - presencia pública del Islam, estos ateos devotos, independientemente de su concepción a cerca de la esfera religiosa, respaldan la necesidad de reafirmar las raíces cristianas-católicas de Occidente en contraste a tal presencia no cristiana (ROLDÁN 2008) ${ }^{6}$.

Lo que se va perfilando es, entonces, un cuadro sociocultural de gran complejidad del cual, sin embargo, emergen nuevos perfiles de identidades culturales y religiosas.

Es en este contexto se colocan los ateos, agnósticos y nones que han sido entrevistados para el presente estudio, personas que se definen "sin religión » pero que han tenido, en la mayor parte de los casos, una socialización religiosa prevalentemente católica, que hace que se deban confrontar permanentemente con la cultura de referencia aún en sus vivencias cotidianas.

\section{La metodologia de la investigación}

Il presente artículo es el resultado de una investigación desarrollada en el marco de otra más amplia cuyo título original es The Transformation of Lived Religion in Urban Latin America: a study of contemporary Latin Americans' experience of the transcendent, a la que luego nos sumamos los equipos de investigación de la Universidad del Deusto, Bilbao, España y la Università Roma Tre, Italia. El objetivo principal fue realizar un estudio comparativo en ciudades de cinco países diferentes: Córdoba (Argentina), Lima, Montevideo, Bilbao y Roma, siguendo como modelo de comparación el estudio realizado por Nancy $\mathrm{T}$. Ammermann (2014) en dos ciudades americanas, Boston y Atlanta.

\footnotetext{
6 Es una posición similar a la de los Teocons estadounidenses. La discusión sobre estos temas comenzó con los ataques a las Torres Gemelas del 11 de septiembre de 2011 y, en general, por la creciente aparición del Islam en la escena pública europea.
} 
En particular, el ensayo aquí presentado se concentra sobre el tema de la no creencia religiosa y vivencia de tal condición, del grupo de personas residentes en la ciudad de Roma, autodeclaradas "ateos", "agnósticos", "nones", esta última categoría es la de los creyentes sin pertenencia ni identificación con ninguna institución religiosa; es decir los "unaffiliated, yet religious" (Zurlo, Johnson, 2016).

En su totalidad, la muestra de Roma no es estadísticamente representativa, pero ha tratado de acercarse a las características estructurales de la ciudad. Se han recogido 80 historias de vidas de personas residentes en la capital italiana, pertenecientes a cinco grupos religiosos y un grupo no-religioso, a saber: 30 católicos; 10 protestantes; 11 musulmanes; 10 ortodoxos; 10 judíos; 9 ateos / agnósticos / nones.

Las principales variables consideradas fueron: género (femenino-masculino), edad $(18 / 29,30 / 59,+60)$, clase social: (baja-media-alta); la zona de residencia (periferia, medio/ centro, centro / zona de residencias) y la nacionalidad (italiana-extranjera).

Para los datos estructurales del grupo aquí analizado: ateos, agnósticos, nones, cfr. Tabla 1.

Tab. 1. Datos estructurales de los ateos, agnósticos, nones, entrevistados en Roma. (Febrero-Julio de 2016)

\begin{tabular}{|c|c|c|c|c|c|c|c|c|c|}
\hline Entrevista & $\begin{array}{c}\text { Auto } \\
\text { identificación }\end{array}$ & Sexo & Edad & $\begin{array}{c}\text { Estado } \\
\text { civil }\end{array}$ & Hijos & Nacionalidad & $\begin{array}{l}\text { Profesión - } \\
\text { oficio }\end{array}$ & $\begin{array}{l}\text { Clase } \\
\text { social }\end{array}$ & $\begin{array}{l}\text { Zona de } \\
\text { residencia }\end{array}$ \\
\hline 1 & atea & $\mathrm{F}$ & $18-29$ & soltera & No & Ita & estudiante & Baja & Periferia \\
\hline 2 & atea & $\mathrm{F}$ & $30-59$ & soltera & No & Ita & bióloga & Media & Medio cento \\
\hline 3 & atea & $\mathrm{F}$ & $30-59$ & soltera & No & Ita & Empleada & Media & Medio centro \\
\hline 4 & atea & $\mathrm{F}$ & +60 & casada & Sí (2) & Ita & $\begin{array}{c}\text { Jubilada } \\
\text { (antes } \\
\text { empleada) }\end{array}$ & Alta & $\begin{array}{c}\text { Centro/zona } \\
\text { residencial }\end{array}$ \\
\hline 5 & atea & $\mathrm{F}$ & $30-59$ & casada & No & Ita & Bibliotecaria & Media & Medio centro \\
\hline 6 & $\begin{array}{c}\text { none } \\
\text { sin religión }\end{array}$ & M & $18-29$ & soltero & No & Ita & $\begin{array}{l}\text { Desocupado } \\
\text { (film maker) }\end{array}$ & Baja & Periferia \\
\hline 7 & agnóstico & $\mathrm{M}$ & $30-59$ & soltero & No & Ita & $\begin{array}{l}\text { Empleado } \\
\text { Sociólogo }\end{array}$ & Baja & Periferia \\
\hline 8 & agnóstico & $\mathrm{M}$ & $30-59$ & soltero & No & Ita & $\begin{array}{l}\text { Investigador } \\
\text { psicólogo }\end{array}$ & Media & Medio centro \\
\hline 9 & ateo & $\mathrm{M}$ & +60 & viudo & Sí (1) & Ita & $\begin{array}{l}\text { Jubilado } \\
\text { (médico) }\end{array}$ & Media & $\begin{array}{l}\text { Medio } \\
\text { periferia }\end{array}$ \\
\hline
\end{tabular}


Con el objetivo de reflexionar sobre los binomios: Individuo/Institución; espiritualidad/religión; autonomía del individuo/influencia de la comunidad de pertenencia, los datos analizados fueron la socialización religiosa, la creencia, la práctica y la experiencia espiritual/trascendente y los valores.

Para este grupo de personas se utilizó el mismo protocolo para las entrevistas a los creyentes de las diversas religiones, es decir se le hicieron las mismas preguntas en los 6 grupos antes mencionados.

En el cuadro siguiente se presentan los temas tratados en cada una de las cuatro dimensiones de la religiosidad, cfr. Tabla 2.

\section{Tab. 2. Las categorías de la religiosidad}

\begin{tabular}{|c|c|c|c|}
\hline CREENCIA & EXPERIENCIA & PRACTICA & PERTENENCIA \\
\hline $\begin{array}{l}\text { 1) } \begin{array}{l}\text { creencia en un } \\
\text { ideal (abstracto); }\end{array} \\
\text { - } \quad \text { Dios } \\
\text { - } \quad \text { eternidad } \\
\text { - } \quad \text { bien y mal } \\
\text { - } \quad \text { paraiso } \\
\text { - } \quad \text { purgatorio } \\
\text { - } \quad \text { infierno } \\
\text { - } \quad \text { pecado } \\
\text { - culpa } \\
\text { 2) creencia-influencia } \\
\text { en la vida cotidiana; } \\
\text { - conciencia individual } \\
\text { 3) dimensión espiritual }\end{array}$ & $\begin{array}{l}\text { - percepciones y } \\
\text { sensaciones de } \\
\text { la presencia y la } \\
\text { acción de un ser } \\
\text { trascendental } \\
\text { - } \quad \text { contacto } \\
\text { con Dios - } \\
\text { percepción de su } \\
\text { presencia }\end{array}$ & $\begin{array}{l}\text { Los indicadores } \\
\text { utilizados fueron: } \\
\text { - misa } \\
\text { - comunión } \\
\text { - confesión } \\
\text { - peregrinajes } \\
\text { - devoción mariana } \\
\text { - devoción a los } \\
\text { santos } \\
\text { - oración } \\
\text { - meditación } \\
\text { - hacerse la señal de } \\
\text { la cruz } \\
\text { - lectura de la Biblia } \\
\text { - lectura de textos } \\
\text { religiosos } \\
\text { - imágenes, } \\
\text { estampitas. } \\
\text {-Vivencia de la } \\
\text { Navidad y la Pascua }\end{array}$ & $\begin{array}{l}\text { Dimensión relacionada } \\
\text { con la identidad } \\
\text { colectiva: } \\
\text { 1) por convicción } \\
\text { personal (compromiso); } \\
\text { 2) por educación o } \\
\text { tradición; } \\
\text { 3) selectiva. } \\
\text { Iglesia / templo / } \\
\text { lugar de culto / con el } \\
\text { cual se siente parte o } \\
\text { identificado } \\
\text { Tipo de relación } \\
\text { con ese lugar y su } \\
\text { comunidad }\end{array}$ \\
\hline
\end{tabular}

El cuestionario para la recolección de datos, que se utilizó en la cinco ciudades antes nombradas, preveía considerar también la concepción sobre el Papa, el Jubileo de la Misericordia, el trabajo, el espacio público, el tiempo libre, la política, el voluntariado. En esta oportunidad se han privilegiado las apenas presentadas categorías de religiosidad, comenzando con el análisis de la socialización religiosa de los entrevistados. 


\section{La vivencia de la no-religiosidad en Roma. Socialización religiosa, creencias y prácticas}

En un primer momento podría sorprender que para analizar "la vivencia de la no-religión" de quienes se definen a sí mismos no-creyentes o no-pertenencientes a ninguna religión, sean utilizadas las categorías clásicas de religiosidad propuestas por la sociología de la religión de las últimas décadas (Glock, 1969; Cesareo et al., 1995; Martelli, 1994, 2002; Roldán 2009).

En el caso de Roma se ha relevado que utilizando, en las entrevistas, el mismo cuestionario que se aplicó con las personas que se identificaban con un credo religioso, se pudieron observar a lo largo de las narraciones de las historias de vida, actitudes de acercamiento y/o distancia respecto a las categorías religiosas, que los entrevistados indentificaban prevalentemente con aquellas católicas.

Es por este motivo que se consideró interesante, a los fines del análisis, considerar también las características de la socialización primaria (en particular, aquella religiosa) realizada ya sea en el propio contexto familiar que en algún ámbito religioso, que en la mayor parte de los casos ha sido en parroquias católicas.

\section{La socialización religiosa ${ }^{7}$}

Las personas entrevistadas para este grupo "no-religioso" en Roma poseen características estructurales diferentes (cfr. tabla 1), a comenzar por la autodefinición: hay quienes se definen ateos, otros agnósticos y un joven se define creyente "sin religión" (lo que aquí llamamos nones). Sin embargo, todos han declarado haber recibido algún tipo de educación religiosa, salvo la entrevistada que trabaja como bibliotecaria. Ella afirma haber crecido en una familia cuyos padres también eran ateos y que provenían de aquella cultura revolucionaria social y política de fines de los años Sesenta. En efecto, esta joven mujer es la única que no recibió algún tipo de socialización religiosa; los demás entrevistados se han preparado en las iglesias católicas de sus barrios para recibir los sacramentos de la Comunión y en algunos casos también de

Las preguntas del cuestionario, respecto al tema de la socialización en general fueron: ¿Qué circunstancia/ Qué persona/s ha/n influido más en su religiosidad/espiritualidad/ convicciones actuales? (Familia, escuela, grupo religioso, amigos u otros). 
la Confirmación. Algunas personas han asistido de niños al oratorio ${ }^{8}$ de su propia parroquia.

Hoy, hablando de aquella experiencia religiosa formativa, algunos entrevistados consideran in modo negativo la socialización católica que han recibido durante la niñez, pero admiten que ésta es parte de la cultura italiana. Existe quien la considera una interiorización realizada con la educación misma. La joven estudiante universitaria, de 22 años de edad, afirmaba:

«Claro, de todos modos quedé bastante influenciada por este adoctrinamiento que he recibido desde que era muy chica».

También se la ve como una hipocresía, una imposición. Es el caso de la mujer bióloga, de 50 años:

«esta religión impuesta casi como algo que debe a la fuerza estar allí ... No está bien dar por descontado que debe ser... ¿Por qué uno tiene que tener una religión a la fuerza?»

Al mismo tiempo esta mujer sostiene que cuando entra en una iglesia siente el ambiente "familiar" y se hace la señal de la cruz como signo de respeto por «aquel de la cruz» (Cristo) al que nunca llama por su nombre per afirma con convinción que con él la sociedad está cambiando. Si es hijo o no de Dios no le interesa, pero sí reconoce el valor moral de sus enseñanzas. En el caso de esta entrevistada la socialización, la cultura católica de base, se releva en su narración sobre el catechismo al que participaba cuando era chica, así como a las misas y actividades en la parroquia; recuerda los amigos que se reunían para tocar música allí y al final de la anécdota, dice: «la iglesia es mi casa». Durante la entrevista usa expresiones como: "igracias a Dios!» y afirma que el «Padre eterno nos da dones y talentos a cada uno de nosotros...».

La religiosidad difusa (Cipriani 2017) de los entrevistados se puede observar también en la concepción que tienen de las festividades religiosas, como por ejemplo de la Navidad. La mujer, de 33 años de edad, empleada, habla de su «origen católico»y explica así el contexto cultural italiano:

\footnotetext{
Oratorio, palabra cuyo origen proviene de la palabra "orar". Hoy se entiende como lugar de actividades formativas y ricreativas reservadas a niños y jóvenes y que se realizan, los fines de semana o también durante la semana, luego del horario escolástico, en las salas de las parroquias católicas.
} 
«Bueno, Navidad es importante para mis padres así que normalmente la paso con ellos y los parientes; digamos que para mí no es fundamental, pero aquí en Italia estamos bastante ligados a estas fiestas; sería un poco extraño si yo abandonara ... ellos lo interpretarían como un abandono...»

También esta persona, como la anterior, usa en su narración expresiones idiomáticas como «jOh Dios!» y «jOh Virgen María!» y nombra a la parábola de los talentos (Evangelio de Mateo, 25: 14-30) cuando se refiere a las caracteristicas, talentos, capacidades de cada persona.

De la importancia cultural de lo religioso en Italia está convencida también la entrevistada de 37 años que trabaja en una biblioteca y realiza actividades multiculturales:

«en Italia, la religión es vista solo como un hecho religioso y no cultural, y en cambio, en mi opinión es un factor absolutamente cultural muy importante».

También esta entrevistada usa la frase «jOh Dios!» durante la entrevista y afirma que de algún modo «vive la religión de reflejo», es decir, que aun siendo atea, a igual de su marido capoverdiano, cuando se reunen con otros amigos viven la religión indirectamente:

«muchas personas que conocemos son de religión católica o musulmana por lo cual de alguna manera vivimos, vivimos la religión y los momentos de religiosidad de los demás indirectamente... cuando, por ejemplo, tenemos amigos musulmanes que vienen a cenar: hay quienes tienen que detenerse por un momento para rezar o por ejemplo no podemos cocinar ciertos alimentos y esto de alguna manera afecta, sin embargo, absolutamente no se lo ve como una intrusión, no en lo absoluto, se lo vide en el mayor de los respetos por el otro y esto no nos pesa absolutamente ...»

Por la misma razón cultural, la joven empleada, de 33 años, dice tomar distancia de la mala costumbre de blasfemiar, es decir pronunciar palabras o expresiones injuriosas contra Dios o las cosas sagradas, que algunas personas tienen (con o sin intensión de ofender), con o sin plena conciencia del significado:

Yo, que no soy creyente, te digo que no apruebo las blasfemias. En general, considero que si tu eres un creyente, no tiene sentido que blasfemes, porque estás blasfemando al Dios en el que crees [...] luego en presencia de las personas, como por ejemplo mi madre, quisiera que los que lo hacen, ique 
no blasfemen! ¡Simplemente porque de esta manera le faltas el respeto a una persona que cree en estas cosas!

\section{La creencia}

Otro aspecto fundamental a analizar en la experiencia de las personas que se autodefinen «ateos », " agnoticos » o «nones » es la creencia o la no-creencia que tienen respecto a lo divino, lo trascendental, lo spiritual. Durante las entrevistas se les ha preguntado sobre la concepción de Dios y Jesucristo; sobre el bien y del mal, sobre el paraiso, purgatorio e infierno; sobre la conciencia personal y la ley de Dios; el pecado y la culpa. Se les pidió que hablaran de la existencia del alma, de la vida después de la muerte, es decir de la eternidad. Se les ha pedido que definan también lo que entienden por la religión y por espiritualidad.

Antes de referirnos a sus concepciones sobre estos temas se ha podido relevar también en algunos casos los motivos de la no-creencia o el abandono de la creencia anterior. Un ejemplo es el de la joven estudiante que afirma que luego de la muerte de su abuela se sintió desilusionada y abandonada:

«inicialmente creía a esta fábula que me habían contato, pero luego de la muerte de mi abuela no tuve más aquella respuesta que encontraba antes, por lo tanto abandoné todo; es más, con un poco rabia también respecto a esta figura [Dios]... luego creciendo, volví a pensar y llegué a la conclución que no creo más. Para mí no existe nada!».

La entrevistada que trabaja como bióloga tiene una idea más definida de su no-creencia. Ella lo considera un elemento esencial de su naturaleza, de su ser, al punto que lo compara con la homosexualidad:

«Cuando era pequeña, pensaba que tenía que ser creyente, ique debía ser creyente! entonces me esforzaba para serlo. Nací en una familia de creyentes y he recibido una educación de creyentes. Pero en mi opinión, jes un poco como ser homosexual! Es decir, aún si te educan con la idea de que debes ser heterosexual, tu sientes desde temprano ique no lo eres! Yo me identifico mucho con esto porque lo siento muy parecido a mi caso, en el sentido que es algo que siempre me han dicho: "tienes que creer", sin embargo yo siempre sentí dentro de mí que mi naturaleza era otra! Así que no ... ¡No creo haber sido nunca realmente una creyente!» 
Pero si de concepciones de lo sagrado se habla, es interesante observar lo que los entrevistados afirman acerca de las distintas temáticas de la creencia (y no-creencia), por ejemplo sobre la imagen o definición que tienen de Dios. La joven estudiante universitaria lo comenta así:

«Yo lo veía como un padre, como un padre de todos pero hoy pienso que no hay nadie porque he conocido mucha fealdad en el mundo en mis pocas experiencias y, por lo tanto, si realmente hay un Dios, no debe ser un Dios tanto bien hecho, jeso es! No! ... Creo que es más una fábula que se le cuenta a los hombres para darles una respuesta ... [...] ¡Sí! Creo que es un cuento de hadas que se le dice al hombre o que se les ha dicho a los seres humanos en general para que se alivien de esa sensación de incertidumbre que tienen por sí mismos o en relación a la salvación; porque el hombre que cree encuentra de algún modo una guía, una guía moral, espiritual, una fuerza a la que aferrarse...»

Esta joven se ve desilusionada: Dios, si existe no es un Dios «bien hecho », no es perfecto, y esto es debido al mal en el mundo. Esta idea es corriente entre quienes hoy se declaran no creyentes, como por ejemplo lo hace la señora de 69 años, de clase alta, esposa de un senador del partido comunista:

«Dios... ¿cómo decirlo? ... está muy lejos.... Dios, este ser ... que realmente no veo manifestarse, porque frente al mal que sucede en la humanidad no tengo respuestas, no veo a Dios...»

Para el hombre de 42 años, psicólogo, que afirma haber asistido al oratorio de la parroquia de su barrio durante toda su niñez, la idea actual de Dios es la de un Dios lejano: «bíblico, no evangélico», relacionado con «el límite de la cultura católica del pecado y la expiación»; por esta figura de Dios él declara se debería sentir miedo:

«Si yo pensara que Dios ha enviado sobre la tierra [el mal], porque de todos modos debemos expiar el pecado original, es un Dios peligroso, en mi opinión. ¡Tendría mucho miedo de creer en un Dios que envía plagas a Egipto! Entre paréntesis yo tengo amigos teólogos, y sé que el bien no se puede lograr mediante un acto de maldad, por lo que para liberar a un pueblo no se lo puede hacer así ... jun Dios que con la última plaga asesina niños inocentes sería ilógico! [...] y por lo tanto, en mi opinión, la idea de la expiación del pecado es el límite principal de la creencia católica» 
Respecto a Jesucristo algunos entrevistados le reconocen el valor moral - más que religioso - de su mensaje. Como se mencionaba anteriormente, la mujer de 50 años, de clase media, que varias veces declara su condición de atea, cuando la entrevistadora le pregunta ¿qué piensas de Jesús ?, ella contesta:

«Lo adoro, pienso de él lo que todos piensan: que sentó las bases de la sociedad moderna [...] él a nivel individual, no tanto político, sino como persona, mostró el camino que no existía antes y todavía estamos siguiendo ese camino; no es que ... inventamos mucho más ... si lees el Evangelio, allí está todo ... ¡está todo! cómo tienes que relacionarte con tu prójimo, cómo debes hacerlo ... pero también las cosas prácticas. Es así, en mi opinión, él fue una persona muy importante. Si es un hijo de Dios o no es el hijo de Dios, para mi no tiene importancia, es un aspecto que no me importa mucho...»

Respecto a la concepción de la eternidad, los entrevistados dieron respuestas diferentes. Hay quienes hablan del alma que queda vagando después de la muerte, otros piensan a la posibilidad de la reincarnación. Y la mujer apenas citata habla de una experiencia que ella define «trascendental» con dos personas fallecidas. La primera con un compañero de trabajo que se le aparece y le habla: cuando ella le dice que no se preocupe por ella y que vaya a ver (que se le aparezca) a su esposa y sus hijos, el amigo le responde: «nosotros los muertos tenemos mucho tiempo». La segunda experiencia que esta entrevistada cuenta es la percepción nítida de la presencia de su padre a través de su perfume en el aire. Tal percepción la tiene en un momento en que se encontraba hablando con su madre en su casa, pero sostiene haberla sentido solo ella.

Esta esperiencia se relaciona también a la idea de la espiritualidad. En efecto, las personas "sin religión” entrevistadas en Roma si bien marcan una distancia con la religión entendida como cultura e identidad afirmada históricamente y otros la ven en modo negativo como una imposición o indoctrinamento, sí recuperan la idea de espiritualidad y lo hacen a través del contacto con la naturaleza, «con el universo». Hay quien la define una fuerza, una potencia de características femeninas:

«me viene a la mente una divinidad femenina, como la Tierra, algo que tenemos frente a nuestros ojos todos los días y que seguramente es muy poderoso ... que emite una fuerza muy poderosa que de alguna manera también nos llega, sin embargo no la veo como una deidad». 
En otros varios casos, la espiritualidad tiene que ver con la relación armoniosa con los demás. La mujer de 69 años, que declara no ver la presencia de Dios por el mal en el mundo, cuando habla de espiritualidad lo hace en estos términos:

«Existe algo que existe dentro del ser humano, que es importante, y que podemos llamar espiritualidad, sensibilidad hacia los demás [...] de espiritualidad son dotadas también las personas que no creen y que hacen cosas importantes para los otros, para los seres humanos...»

Se puede relevar en estos casos que el ateísmo, o la no-creencia en general, no necesita negar completamente la espiritualidad o declararse adversario de ella, en particular, cuando esta dimensión en interpretada como una sensibilidad y atención hacia el sufrimiento del mundo. Como sostiene Luigi Berzano (2017), analizando el tema del ateísmo en la sociedad secular: «sólo la visión espiritual del mundo y de la vida puede evitar que el ateísmo se convierta en algo fanático y ciego» (Berzano, 2017, p. 85). Se trata de nuevas sensibilidades espirituales con nuevos símbolos y acciones. Es la multiplicación de la vivencia de las dimensiones de la trascendencia, de la ética y de lo social.

\section{La práctica}

La práctica religiosa anterior, realizada en la mayor parte de los entrevistados cuando eran niños o jóvenes, fueron principalmente hechas en un contexto católico, fruto de la socialización familiar y religiosa, precedentemente analizada. Las prácticas más comunes fueron la participación a la misa, la confesión, la preparación para recibir los sacramentos de la Comunión y Confirmación. Hay quienes recuerdan haber hecho algún peregrinaje y varios hablan de la oración. Come mencionado más arriba, algunos lo narran con serenidad, como parte de una tradición familiar, otros son más críticos y consideran que esas prácticas fueron consecuencia de una visión obtusa y/o de una actitud de imposición.

Hoy, concientes de la propria identidad, ya sea que se consideren una persona atea o agnóstica o creyente sin religión, nones, los entrevistados en la Ciudad Eterna, hablan de prácticas que podemos dividir en dos clases: la primera, no perteneciente o lejana del catolicismo ; la segunda, caracterizada per la presencia de reminicencias católicas. 
En el primer grupo se colocan las prácticas de sabores orientales que buscan la «felicidad interior » y los beneficios de encontrar un equilibrio fisico-mental. Aquí se pueden nombrar la meditación trascendental, el Yoga, las actividades para el potencionamiento humano (empowerment). Sin embargo, éstas no son vividas como prácticas espirituales.

Un ejemplo es el de la joven empleada de 33 años que lo explica de esta manera :

«una vez descubrí el yoga y me enamoré enseguida de esta práctica y ahora digamos que trato de usarla tanto como me sea posible porque me hace sentir mejor conmigo misma, incluso cuando estoy sufriendo por alguna razón. Vuelvo a casa y si he sufrido por algo que sucedió durante el día o porque el cansancio me causa un pesimismo cósmico, entonces me pongo allí, hago yoga y no sé, me siento empowered (potenciada), siento que tengo más control de mi vida. Siento que estoy haciendo algo por mí, [me siento más independiente!»

Solo la joven universitaria declara practicar lo que comúnmente es definido una religión: el budismo. Ella, sin embargo lo hace por considerarlo «una adoración de sí misma» y aclara: «es decir, tu Dios sos vos misma, por esto [el budismo, entendido en este modo] es más cercano a mis ideales». Le interesan las religiones en general, pero la cultura oriental en particular porque, según ella, los principios son « más solidarios, más humanos» y le da una idea de libertad también en la practica: lo hace cuando quiere, sin restrinciones de días y horarios. Y aun así no lo considera una "verdad absoluta"; lo mismo afirma sobre la meditación: para ella la regulación del respiro comporta solo beneficios físicos.

Las prácticas que tienen alguna reminiciencia católica como hacerse la señal de la cruz por respeto, el ir a misa para acompañar algún amigo, se unen a aquella más comunmente realizada por los entrevistados, como es la oración, es decir rezar. Hay quienes lo hacen repitiendo una frase en chino antiguo e un momento grupal para hacer emerger las "energias positivas", expulsando aquellas negativas, o en la forma más clásica del catolicismo para pedir ayuda o protección en momentos de dificultad. La señora de clase alta afirmaba, como disculpándose por haber rezado alguna vez en momentos de necesidad: «es un poco cómodo, lo sé, pero quizás esto también es humano, por esto... bueno, aceptamos esto... el ser humano es tan débil que solo, ¿̇ qué puede hacer?» 


\section{La búsqueda del sentido. La dimensión de la experiencia y los valores.}

Buscar un sentido a la propia vida es lo que hacen los individuos, dentro y más allá de los confines de una religión. El horizonte simbólico de lo religioso es, para muchos, una plataforma de significado en la cual experimentar aquella dimensión de lo trascendente que se presenta como complementaria respecto al plano de la racionalidad. Por su naturalezza, el hombre es atraído por un más allá que constituye el atractor ${ }^{9}$ en base al cual comprometerse y actuar de manera significativa en su propia realidad. Además de las experiencias religiosas tradicionales, la búsqueda de sentido adquiere rasgos subjetivos y originales. ¿Qué es lo que constituye un vehículo de trascendencia para el hombre contemporáneo que se autodefine ateo, agnóstico o nones?

Lo que surge de esta investigación, confirmando los datos de otros sondajes significativos (Garelli, Guizzardi, Pace, 2003; Garelli, 2006) es que definirse tales no excluye a priori la búsqueda de una dimensión trascendental. Es interesante entonces detenerse en las palabras de nuestros entrevistados e intentar captar, en sus respuestas, el significado plural de la cuarta dimensión de la religiosidad

\section{La experiencia religiosa}

Las preguntas del protocolo de las entrevistas intentaban analizar esta dimensión y estaban hechas como estímulo al diálogo con cada entrevistado, independientemente de su autodefinición ${ }^{10}$. Particularmente interesante es lo que surge en las respuestas de aquellos que se autopresentan como ateos, agnósticos o nones. Lo que emerge nos permite comprender la singularidad de las experiencias, identificar puntos de convergencia y divergencia respecto a una tradición culturalmente definida y todavía muy enraigada en la realidad italiana como es el catolicismo.

\footnotetext{
$9 \quad$ El término "atractor" es un término matemático y representa un conjunto hacia el cual un sistema dinámico evoluciona después de un tiempo suficientemente largo. La descripción de los atractores de sistemas dinámicos caóticos ha sido uno de los éxitos de la "teoría del caos" y se usa, con un significado que se utiliza también en otras áreas, incluidas las ciencias humanas, como la psicología y la sociología.

10 Las preguntas sobre la experiencia religiosa fueron: ¿Cómo y cuándo siente tener contacto con Dios / con la trascendencia? ¿Cómo siente su presencia? ¿Ha habido algún episodio importante? [¿Ha habido algún milagro?]
} 
Los elementos para interpretar la experiencia surgen en varias partes de las entrevistas que, según lo previsto por la metodología utilizada, son muy libres y permiten la maleabilidad de las diversas dimensiones, dependiendo de la fluidez de la narración de cada uno de los entrevistados.

En la muchacha estudiante, de 22 años que se define como atea, se releva una constante búsqueda que le ha llevado a experimencias de participación en una comunidad religiosa católica. Hoy ella narra su participación en un grupo budista. Hace uso de drogas ligeras y le gusta contemplar la naturaleza y es en esta contemplación que ella declara experiementar un contacto « con el universo »:

«Yo ... será una tontería decirlo, pero siento un contacto, algo que creo que es más una especie de madre naturaleza, una entidad que no es exactamente divina, omnipresente, omnisciente. Por ejemplo, yo vivo en el campo, entonces cuando estoy en medio de la naturalezza, cuando miro, no sé, el cielo que cambia o el sol, el atardecer o el florecimiento de las plantas, siento como una especie de emoción que me da ... es una sensación de contacto con el universo...»

En todos los entrevistados está presente el sentimiento de atención al prójimo; el límite está en la conciencia individual y el respeto por el otro. Incluso para esta estudiante, uno de los valores más importantes ${ }^{11}$ es el respeto:

«el respeto, jes lo primero! Hacia sí mismos y hacia los demás, porque cuando te respetas a tí mismo, es fácil, respetar a los otros».

Por otro lado, y a pesar de su autodefinición de atea y su crítica del concepto de creencia en Dios, la entrevistada bióloga, de 50 años, está abierta a la experiencia de la trascendencia y narra dos episodios en los que vivió en esta dimensión: fueron momentos diferentes en los cuales percibió la presencia de personas fallecidas; cuando se le preguntó sobre los valores, ella respondió: «Mis valores son tratar de vivir dando ... dando ... no solo recibiendo».

Una vez más emerge la atención hacia el prójimo, a pesar de que esta entrevistada y la anterior expresan ese concepto en modo limitado solo a algunas personas que ellas consideran "meritorias" de sus atenciones.

La mujer empleada, de 33 años afirma:

«obviamente yo no siento ninguna presencia divina, eso está claro. De vez en

11 Valores / virtudes: ¿Cuáles son los valores más importantes para Ud.? ¿Por qué esos? ¿Los transmite a sus hijos / los demás? 
cuando me gusta jugar con... con este tipo de figura que yo llamo vida, ¿no? [...] Pero yo no ... ¡No quiero humanizar la vida, como si fuera una especie de Dios que decide mi destino!».

Y estimulada a pensar en su propio concepto de trascendencia, dice:

«La religiosidad me parece un poco más obtusa [...] mientras que la espiritualidad me parece un poco más, no sé, yo diría "razonable", aunque internamente, sentida internamente, algo que te hace sentir mejor acerca de ciertas cosas, un pensamiento profundo sobre ti mismo, sobre lo que te rodea».

También para ella, uno de los valores más importantes es el "respeto mutuo": «tratar de no hacer sufrir a los demás por mi causa». La amistad y el amor son otros valores que considera y luego aclara: «No sé cuánto y cómo se manifiesta en mi vida, ipero me encantaría pensar que el amor es un valor mio!». Para ella esto implica tener una relación con los demás, con el prójimo.

El mismo concepto es expresado por la entrevistada de clase alta, de 69 años de edad. Ella declara de no ver la presencia de Dios en el mundo, por el mal que reina, pero habiendo hecho un curso de formación religiosa con los salesianos, a quien se acercó con la intensión de hacer algo por los demás - que luego se tradujo en una experiencia de solidaridad vivida directamente en África - declara:

«la única fuerza que me dan las palabras de Jesús son: “ámense los unos a los otros". Es decir, los seres humanos, paradójicamente, si queremos extremizar, en lugar de dirigirnos a Dios... - en el sentido de este Dios que yo no veo presente - entonces vería una mayor comunicación entre los seres humanos, ayudándonos los unos a los otros, entre los seres humanos».

Otra mujer de 37 años, cuando habla de los valores más importantes para ella afirma que:

«en el sentido general, sin duda la honestidad es ciertamente un valor para mí, también, el hecho de ayudar al próimo, saber ayudar a los demás es una virtud, es un valor». Es interesante observar que para ella, nuevamente, el sentido de la trascendencia emerge en el concepto de la «naturaleza»: «una idea como tienen los japoneses de esta fuerza de la naturaleza, que es además un poco también parte de la cultura china: la de unir a todos los seres humanos [ ...] La naturaleza tiene su propósito, trabaja en una determinada dirección, por lo que si sabemos cómo sentirla de alguna manera, sin duda podemos obtener grandes beneficios y esto es algo espiritual, sobrenatural sin duda». 
La idea de la naturaleza se encentra también en el joven de 26 años que se define creyente sin religión, un nones. Se percibe en él la fuerte socialización católica recibida, pero el entrevistado reitera la distancia que toma del catolicismo institucional. También para para él es en la naturaleza donde se siente en contacto con Dios.

Cuando se le preguntó acerca de la trascendencia, recuerda un episodio en particular en el que, por diversas circustancias, no se encontró en Aquila durante el último terremoto en esa ciudad del centro de Italia, cuando una pared del apartamento que compartía con otros estudiantes colapsó justo sobre su cama. Da a entender que se trata de un milagro favorecido también por la devoción de su madre y el hecho de tener, él mismo, una estampita de San Gabriel, el protector de los estudiantes, siempre en su portafolio. Y luego aclara que los valores más importantes son:

«el respeto por los demás dentro de ciertos límites, por supuesto, el respeto por el pensamiento, opinión de los demás, especialmente cuando se trata de religiones. [...] si hay respeto, logramos vivir todos, luego más o menos, cada uno tiene su concepción de bien y mal, es suficiente que su idea de bien no perjudique la mía; por el resto, él puede hacer lo que quiera».

La amistad, la sinceridad y el amor en general, el amor a uno mismo y el amor a los demás, en consecuencia son los valores expresados por el entrevistado de 36 años, sociólogo, que se autodefine agnóstico, para él:

«la trascendencia en general es algo que me da serenidad, digamos, es decir, el hecho de pensar que hay alguien que, de alguna manera, guía tu destino, guía un poco tus pasos, etc., me da serenidad, me hacen sentir menos solo».

El agnóstico, psicólogo de 42 años de edad, encuentra difícil definir algo preciso como valor. Él menciona la ética, la moralidad, el hecho de no hacerle a los demás lo que uno no quiere que le hagan, pero aclara que la "disponibilidad" que debería caracterizar a un buen cristiano es una tontería ya que es necesario encontrar un «equilibrio entre lo que es la disponibilidad hacia los demás y los límites» consecuentes de las propias exigencias personales.

Este entrevistado, según el cual Dios es considerado como el «principio de la creación», afirma experimentar una especie de contacto con la trascendencia en la espeleología y las actividades subacuáticas (buceo) que él realiza, en donde los sentidos que normalmente no se utilizan se desarrollan en ese momento en un modo especial. Él lo explica de este modo: 
«ahí, entras por un momento con algo que es otra cosa, diferente de ti en general y lo percibes mucho más y eso, en mi opinión, es el contacto con la creación».

Por otro lado, el médico de 86 años, que se define ateo, cuando se le pregunta acerca de su dimensión espiritual, responde:

«yo siempre me lo pregunto, y esto puede ser considerado la dimensión spiritual: ¿hay cosas que si se hacen pueden ofender o dañar mi ... si queremos usar este término, mi "prójimo"? Si es así, esto no es bueno. Ésta es mi dimensión espiritual. La otra cosa que trato de hacer, si puedo, es ayudar a quien lo necesite ya sea desde un punto de vista psicológico que material, no económico, es decir, ayudar a quien se encuentra en problemas. Lo hago porque me parece que es correcto ayudar al prójimo... ».

Es interesante notar la idea y la práctica muy difusa de "amar al prójimo”. El lenguaje, al expresar este concepto, está muy cerca de los "mandamientos" bíblicos, en particular el segundo mandamento que Jesucristo expresa en el Nuevo Testamento, luego de afirmar, en primer lugar, el mandamento de amar a Dios sobre todas las cosas.

En resumidas cuentas se puede relevar en las biografías de los entrevistados en la ciudad de Roma, como emerge en sus palabras, gestos y acciones directa o indirectamente la cultura religiosa que en Italia manifiesta su peso e influencia aun en la terminología utilizada para expresar los conceptos laicos del respeto por los demás, la solidaridad, el bien común.

\section{Conclusiones}

En lo específico del caso italiano se puede observar que la formación católica, como proceso de socialización primaria, se convierte en parte de la identidad de los individuos y allí permanece independientemente de sus elecciones de vida. En lo específico de la investigación cuyos resultados aquí presentamos, las autodefiniciones de las personas entrevistadas se colocan, a primera vista, en una posición alejada del modelo tradicional de religión y del catolicismo. Sin embargo, no se puede afirmar que estas autodefiniciones sean tajantes y no dejen lugar a la coexistencia de algún tipo de trascendencia en la vida de estos romanos.

El cambio y la transformación parece ser una constante en la realidad 
de individuos, sujetos a tensiones constantes en los procesos de socialización secondaria y que en la contemporaneidad globalizada aumentan cuantitativa y cualitativamente. Como señalan Berger y Luckmann (2004, p.190) «la socialización nunca es total y nunca se acaba» y para reforzar esta tesis agregan: «siempre existe la angustia de la metamorfosis [...].existe, además la amenaza directa a las definiciones rivales de la realidad con la que uno puede entrar en contacto en la sociedad» (Ivi, p. 202).

A este punto parece lícito cuestionarse: ¿se puede hablar de "espiritualidad sin Dios"?; ¿el ateísmo y la espiritualidad pueden coexistir en el pluralismo que caracteriza, por ejemplo, nuestros actuales contextos sociales? Según la literatura sociológica, (Berzano, 2017; Stoltz et a.l 2016; Garelli 2011; Bullivant 2008; Bainbridge 2005) se trata de dos elementos, dos polos que pueden coexistir, incluso entrecruzarse en la atención hacia los demás, en la acción positiva dirigida a aliviar los sufrimientos del mundo. «Esta posibilidad de una relación creativa y fértil entre el ateísmo y la espiritualidad ha sido propuesta, entre otros, por Raimon Panikkar (2004), un feroz defensor de la necesidad de preservar la tensión fructífera entre el Yo secular y el Yo espiritual. [...] El primero sigue siendo el polo del tiempo acabado y de la vida cotidiana, el segundo es el polo del infinito, de la alteridad y de la trascendencia» (BERZANo, 2017, p. 85). Ambos pueden ser alojados al interior del hombre o la mujer contemporáneos, aun cuando toman distancias de las instituciones religiosas, de las creencias y las prácticas tradicionales pero no renuncian a redefinir y a vivir una dimensión que los lleve al bienestar personal y a colaborar a la realización general del bien común con los demás.

\section{Bibliografía}

ALLIEVI S., Come si costruisce il conflitto culturale. La percezione dell'Islam nello spazio pubblico europeo, Religioni e Società, n. 52, 2005, pp. 6-15.

ALLIEVI S., Ritorno delle religioni, scoperta delle differenze, Reset, n.97,2006, pp.34-37. AMMERMAN N.T., Sacred Stories, Spiritual Tribes. Finding Religion in Everyday Life. Oxford: Oxford University Press, 2014.

BAINBRIDGE W.S. Atheism. Interdisciplinary Journal of Research on Religion, 1, 2, 2005, pp. 1-26.

BASTIAN J-P. La modernité religieuse en perspective comparée. Europe latine - América latine. Karthala, 2001.

BAUMAN Z., Modernità Liquida. Roma-Bari: Laterza, 2006. 
BERGER P., The Many Altars of Modernity: Toward a Paradigm for Religion in a Pluralist. Boston \& Berlin: Walter de Gruyte, 2014.

BERGER P. L., LUCKMANN T., La realtà come costruzione sociale. Boloña: il Mulino, 2004.

BERZANO L., Spiritualità. Moltiplicazione delle forme nella nella società secolare. Vignate: Rotomail, 2017a.

BERZANO L, Spiritualità senza Dio? Milán: Mimesis, 2017b.

BERZANO L, GENOVA C., Sociologia dei lifestyles. Roma: Carocci, , 2017c.

BULLIVANT, S. Research Note: Sociology and the Study of Atheism.Journal of Contemporary Religion, 23, 3, 2008pp. 363-368.

CESAREO V., ET AL., La religiosità in Italia. Milano: Arnoldo Mondadori Editore, 1995.

CIPRIANI R., Diffused Religion. Cham: Palgrave Macmillan, 2017.

DIOTALLEVI L., Fine corsa. La crisi del cristianesimo come religione confessionale. Boloña: Edizioni Dehoniane, 2017.

GARELLI F., L'Italia cattolica nell'epoca del pluralismo. Boloña: il Mulino, 2006.

GARELLI F., Religione all'italiana. L'anima del paese messa a nudo. Boloña: il Mulino,, 2011.

GARELLI, F., Piccoli atei crescono. Davvero una generazione senza Dio? Boloña: il Mulino, 2016.

GARELLI F., GUIZZARDI G., PACE E. (A CURA DI), Un singolare pluralismo. Indagine sul pluralismo morale e religioso in Italia. Boloña: il Mulino, 2003.

GLOCK, C. Esiste un risveglio religioso negli Stati Uniti?. In R. Boudon, F. Lazarsfeld (compiladores), L'analisi empirica nelle scienze sociali. Boloña: il Mulino, 1969.

LUCÀ TROMBETTA P., Il bricolage religioso. Sincretismo e nuova religiosità, Edizioni Dedalo, Bari, 2004.

MAGISTER S., Il supermarket delle religioni. A cosa credono gli italiani, www.chiesa. espressonline.it, Notizie, analisi, documenti sulla Chiesa cattolica, a cura di Sandro Magister, Roma, 2/07/1998.

MARTELLI S. L'arcobaleno e i suoi colori. Dimensioni della religiosità, modelli di chiesa e valori in un'area a diffuso benessere (Mantova), Milán: FrancoAngeli, 1994.

MARTELLI S. Dissonanze ed armonie. Riflessione sulla costruzione di un indice multidimensionale di religiosità giubilare. In CIPOLLA C., CIPRIANI R. (a cura di), Pellegrini del Giubileo, Milán: FrancoAngeli, 2002.

PISATI M., MARCHISIO R., L'analisi delle economie religiose, Polis, 12(1), 1998, pp. 5-10.

ROLDÁN V. Il Rinnovamento carismatico cattolico. Uno studio comparativo Argentina-Italia. Milán: FrancoAngeli, 2009. 
ROLDÁN V., Religión y política en Italia, en MALLIMACI F. (compilador), Religión y política. Perspectivas desde América Latina y Europa. Buenos Aires: Editorial Biblos, 2008, pp. 59-70.

SCOTTI S., A modo mio. Profili del cattolicesimo nel Mugello contemporaneo. Milán: FrancoAngeli, 2002.

STARK R., INTROVIGNE M., Dio è tornato. Indagine sulla rivincita delle religioni in Occidente. Casale Monferrato: Edizioni Piemme, 2003.

SORBI P., Né ateo né devoto, Intervista di Paolo Sorbi al Direttore de "Il foglio" Giuliano Ferrara, Tempi, n.17, del 26/04/2007. http://www.tempi.it/n-ateo-n-devoto\#.Wa7FQ9NJaRs STOLZ, J. et al. (Un)Believing in Modern Society. Religion, Spirituality, and Religious-Secular Competition. London: Routledge, 2016.

ZURLO G, JOHNSON T.M. Unaffiliated, Yet Religious: A Methodological and Demographic Analysis. Annual Reiew of the Sociology of Religion. V.7, 2016, pp.50- 74. 
32 Verónica Roldán; Simona Scotti

Estudos de Religião, v. 31, n. 3 • 9-31 • set.-dez. 2017 • ISSN Impresso: 0103-801X - Eletrônico: 2176-1078 
34 Verónica Roldán; Simona Scotti

Estudos de Religião, v. 31, n. 3 • 9-31 • set.-dez. 2017 • ISSN Impresso: 0103-801X - Eletrônico: 2176-1078 